\title{
Do Expression Profiles of Cytokines VEGF, TNF- $\alpha$, IL-1 $\beta$, IL-6 and IL-8 Correlate with Gallbladder Cancer?
} Chaturmohta $A^{1}$, Dixit $R^{1}$, Narayan $G^{2}$, Gupta $\mathrm{P}^{1}$, Prasad SB ${ }^{2}$, Yadav $S^{2}$ and Shukla VK ${ }^{* 1}$

${ }^{1}$ Departments of General Surgery, Institute of Medical Sciences, Banaras Hindu University Varanasi, India

${ }^{2}$ Molecular and Human Genetics, Faculty of Science, Banaras Hindu University Varanasi, India

*Corresponding author: Shukla VK, Department of General Surgery, Institute of Medical Sciences, Banaras Hindu University, Varanasi - 221 005, India, Fax: +91 542 2368163, 2367568, Tel: +91 542 2309512, E-mail: vkshuklabhu@gmail.com

Citation: Chaturmohta A, Dixit R, Narayan G, Gupta P, Prasad SB, et al. (2015) Do Expression Profiles of Cytokines VEGF, TNF- $\alpha$, IL-1 $\beta$, IL-6 and IL-8 Correlate with Gallbladder Cancer? J Cancer Sci Clin Oncol 2(2): 202. doi: 10.15744/2394-6520.2.202

Received Date: February 25, 2015 Accepted Date: June 08, 2015 Published Date: June 10, 2015

\begin{abstract}
Aim: Gallbladder carcinoma is a multifactorial disease with a complex interplay at molecular levels. Here we look at the expression of specific cytokines (TNF- $\alpha$, IL-1 $\beta$, IL-6, IL-8 and VEGF) in GBC patients to develop them as biomarkers of gallbladder cancer.

Methods: This study consisted of newly diagnosed cases of Gallbladder Cancer (GBC) $(n=25)$ and cholelithiasis $(n=25)$ as control. Total RNA was isolated from tissue by using TRI-reagent and mRNA expression levels of five above mentioned cytokines were seen by Reverse Transcriptase PCR (RT-PCR). The degree of over expression is correlated with tumour size, staging, differentiation, serosal invasion and metastasis of the disease by application of Chi-square and Fischer $\mathrm{T}$ tests.
\end{abstract}

Results: We found that IL- $1 \beta$, TNF- $\alpha$, IL- 8 and VEGF mRNA expression was upregulated in gallbladder cancer cases as compared with control. IL- $1 \beta$ overexpressed in $65.3 \%$ cases and the statistical difference was significant $(p=0.0012)$. TNF- $\alpha$ was also upregulated in $69.6 \%$ $(p=0.002)$. Overexpression of IL- 8 was seen in $47.8 \%$ of the malignant samples $(p=0.0082)$ and $52.17 \%(p=0.034)$, thus significant. Overexpression of VEGF was observed in $52.17 \%$ of the malignant samples ( $\mathrm{p}=0.034)$ whereas IL-6 showed no expression.

Conclusion: These cytokines expression showed a higher expression level in gallbladder cancer and it also increase with the advance stage. Further studies are needed to establish the relationship between them.

Keywords: Cytokines; Gallbladder cancer (GBC); Cholelithiasis; IL-1 $\beta$; TNF- $\alpha$; IL-8

\section{Introduction}

Carcinoma of the gallbladder (GBC) is the most common biliary tract tumour and is known as the fifth most common gastrointestinal tract cancer in India. The symptoms of GBC are non-specific and this non-specificity of symptoms is responsible for delayed diagnosis: in fact, this tumour is usually identified at an advanced stage when it has already become unresectable [1]. Therefore, prognosis of GBC is poor and only less than $5 \%$ of the patients survives five years postoperatively $[2,3]$.

Cytokine or immunocytokine is a generic name used to describe a diverse group of soluble proteins and peptides which act as humoral regulators at nano to picomolar concentrations. They are known as the main culprit molecules in the pathway of progression from acute inflammation to chronic inflammation and from chronic to carcinogenesis [4]. Cancer cells can respond to host-derived cytokines that promote growth, attenuate apoptosis and facilitate invasion and metastasis. A more detailed understanding of cytokine-tumour cell interactions is the need of time as it provides new opportunities for improving cancer immunotherapy [5].

Our study investigated the behavior of five cytokines whose role in GBC has not yet been clearly established [6]. Studies which are available are confined with cholangeocarcinoma or biliary tract cancer. So far, not much work has been done in relation with these markers in GBC and small amount of data is available from India on the expression of these biomarkers in GBC. The present study was conducted to observe the expression levels of IL1- $\beta$, TNF- $\alpha$, IL- 6 , IL- 8 and VEGF in GBC and to find their association with the clinicopathological profiles.

\section{Materials and Methods}

\section{Samples}

Newly diagnosed twenty five patients of GBC as cases and 25 patients of cholelithiasis as control group were included consecutively in the study from September 2011 to July 2013 after obtaining informed consent from the patients. All the cases were histopathol- 
ogically proven. Tissue samples were collected from both the groups and snap frozen at $-80{ }^{\circ} \mathrm{C}$ (deep freezer). The study was approved by the institute ethics committee.

\section{Isolation}

Total RNA was isolated by using TRI Reagent ${ }^{\oplus}$ (Ambion ${ }^{\oplus}$ by life technologies) as given in the protocol. cDNA was synthesized by using high capacity cDNA synthesis kit (Applied Biosystems). cDNA was amplified with the help of PCR by using gene specific primers. PCR amplification samples were electrophoresed in agarose gel (Table 1).

\begin{tabular}{|c|c|l|c|c|c|}
\hline S. No. & Gene & \multicolumn{1}{|c|}{ Primer sequence } & Ta & Cycles & Product \\
\hline 1. & IL-8 & $\begin{array}{l}\text { F5'-CTGCGCCAACACAGAAATTA-3' } \\
\text { R5'CATCTGGCAACCCTACAACA-3' }\end{array}$ & $53^{\circ} \mathrm{C}$ & 32 & $234 \mathrm{bp}$ \\
\hline 2 & IL-6 & $\begin{array}{l}\text { F5'-TGAACTCCTTCTCCACAAGC-3' } \\
\text { R5'-CTGAAGAGGTGAGTGGCTGT-3' }\end{array}$ & $51^{\circ} \mathrm{C}$ & 36 & $150 \mathrm{bp}$ \\
\hline 3 & VEGF & $\begin{array}{l}\text { F5'-GAGACCCTGGTGGACATCTT-3' } \\
\text { R5'-CTCCTATGTGCTGGCCTTG-3' }\end{array}$ & $54{ }^{\circ} \mathrm{C}$ & 30 & $190 \mathrm{bp}$ \\
\hline 4 & TNF- $\boldsymbol{\alpha}$ & $\begin{array}{l}\text { F5'-CCTGGAAAGGACACCATGAG-3' } \\
\text { R5'-GCCAGAGGGCTGATTAGA }\end{array}$ & $57^{\circ} \mathrm{C}$ & 40 & $236 \mathrm{bp}$ \\
\hline 5 & IL-1 $\boldsymbol{\beta}$ & $\begin{array}{l}\text { F5'-AGGCTGCTCTGGGATTCTCT } \\
\text { R5'-CCCTTGCTGTAGTGGTGGTC }\end{array}$ & $56^{\circ} \mathrm{C}$ & 37 & $236 \mathrm{bp}$ \\
\hline
\end{tabular}

Table 1: Primer sequences of genes including Ta, number of cycles of PCR and product size

\section{Statistical Analysis}

Densitometric value of gene of interest was normalized with densitometric value of housekeeping gene $\beta$-actin by taking the ratio of gene of interest and $\beta$-actin. Mean and standard deviation of control sample were calculated. The normalised value of tumor was compared with 'Mean $\pm 2 x S D$ '. Sample showing value more than 'Mean $+2 x S D$ ' were supposed to be up regulated, less than 'Mean-2xSD' down regulated and rest were treated as showing no significant change. The degree of over expression is correlated with tumour size, staging, differentiation, serosal invasion and metastasis of the disease by using Chi-square and Fischer T tests.

\section{Results}

\section{Patients Demographics}

The mean age in the GBC group of our patients was $52.08 \pm 12.8$ years (range $20-72$ years) whereas in the cholelithiasis was $47.96 \pm 13.4$ years (range 22-70 years). The study comprised of 17 (68\%) females and 8 (32\%) males in the GBC group while 19 (76\%) female and 6 (24\%) male patients in the cholelithiasis group. Thus, the male to female ratio was 2:1 and 3:1 in the GBC and cholelithiasis group, respectively (Table 2 ).

\begin{tabular}{|c|c|c|}
\hline Characteristics & Gallbladder Cancer (\%) $\mathbf{n}=\mathbf{2 5}$ & Cholelithiasis (\%) $\mathbf{n}=\mathbf{2 5}$ \\
\hline Symptoms & & $21(84 \%)$ \\
\hline Pain & $6(24 \%)$ & 0 \\
\hline Jaundice & $16(64 \%)$ & 0 \\
\hline Lump abdomen & $4(16 \%)$ & $4(16)$ \\
\hline Fever & $5(20 \%)$ & 0 \\
\hline Vomiting & $15(60 \%)$ & 0 \\
\hline Anorexia & $15(60 \%)$ & 0 \\
\hline Weight loss & $16(64 \%)$ & NA \\
\hline Hepatomegaly & & \\
\hline TNM stage & 0 & \\
\hline T1 & $4(16 \%)$ & \\
\hline T2 & $12(48 \%)$ & \\
\hline T3 & $9(35 \%)$ & \\
\hline T4 & $5(20 \%)$ & \\
\hline N0 & $20(80 \%)$ & \\
\hline N1 & $20(80 \%)$ & \\
\hline M0 & $5(20 \%)$ & \\
\hline M1 & & \\
\hline
\end{tabular}




\begin{tabular}{|c|c|c|}
\hline Characteristics & Gallbladder Cancer (\%) $\mathbf{n}=\mathbf{2 5}$ & Cholelithiasis (\%) $\mathbf{n}=\mathbf{2 5}$ \\
\hline Stage & 0 & \\
\hline Ia & $4(16 \%)$ & NA \\
\hline Ib & $1(4 \%)$ & \\
\hline IIa & $11(44 \%)$ & \\
\hline IIb & $4(16 \%)$ & \\
\hline III & $5(20 \%)$ & \\
\hline IV & & \\
\hline Histology & $25(100 \%)$ & $1(4 \%)$ \\
\hline Adenocarcinoma & 0 & $2(8 \%)$ \\
\hline Chronic cholecystitis & 0 & \\
\hline Acute cholecystitis & 0 & NA \\
\hline Xanthogranulomatous cholecystitis & & \\
\hline Differentiation & $6(24 \%)$ & \\
\hline Well differentiated & $4(16 \%)$ & \\
\hline Moderately differentiated & & \\
\hline Poorly differentiated & & \\
\hline
\end{tabular}

Table 2: Clinical characteristics of gallbladder cancer and cholelithiasis group

\section{Gene Expression Analysis}

Out of total 50 tissue samples (25 each from GBC and cholelithiasis) collected, 23 cases and 22 controls RNA was considered good for RT-PCR and expression analysis (Table 3).

\begin{tabular}{|c|c|c|c|c|}
\hline \multirow{2}{*}{ S.No. } & \multirow{2}{*}{ Genes } & \multicolumn{2}{|c|}{ Groups } & \multirow{2}{*}{ p-value } \\
\cline { 3 - 4 } & & GBC (\%) & Cholelithiasis & \\
\hline 1 & IL-1 $\beta$ & $15 / 23(65.3)$ & No & 0.0012 \\
\hline 2 & TNF- $\alpha$ & $16 / 23(69.6)$ & No & 0.002 \\
\hline 3 & IL-8 & $11 / 23(47.8)$ & No & 0.0082 \\
\hline 4 & VEGF & $12 / 23(52.17)$ & No & 0.034 \\
\hline 5 & IL-6 & Nil & No & - \\
\hline
\end{tabular}

Table 3: Expression analysis of five cytokines [IL- $1 \beta$, TNF- $\alpha$, IL-8, IL-6 and VEGF] in both groups [GBC and cholelithiasis]

IL-1 $\beta$ : IL-1 $\beta$ over expression has been observed in $65.3 \%(15 / 23)$ of the malignant samples $(\mathrm{p}=0.0012)$. A strong association was observed between IL- $1 \beta$ and differentiation, liver metastasis and a linear correlation between IL- $1 \beta$ and omental metastasis of gall bladder cancer (Table 4) (Figure 1).

\section{L $-\mathbf{1} \beta$}
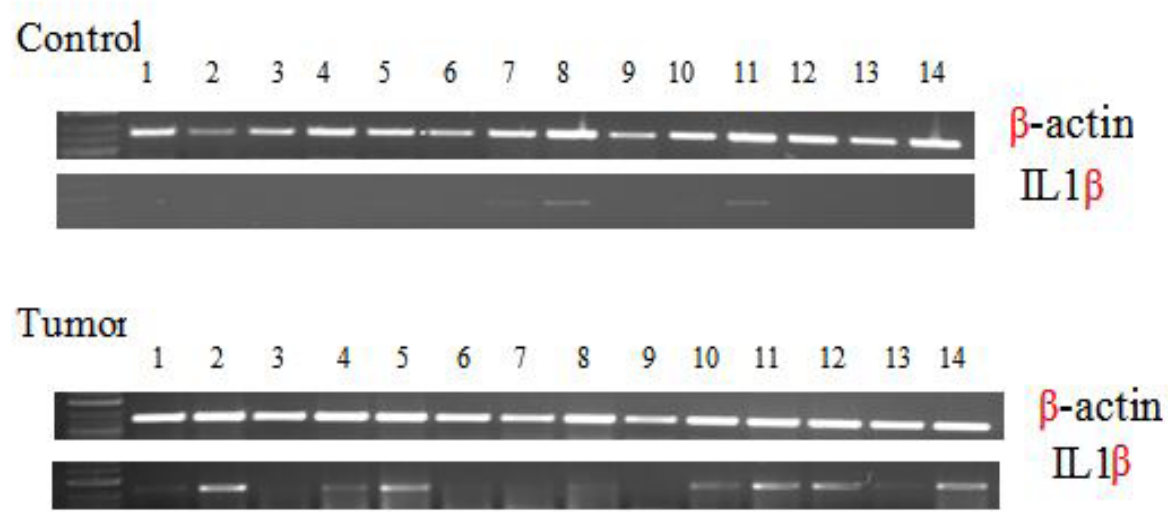

Figure 1: Image showing the positive expression of IL-1 $\beta$ in cholelithiasis (control) and GBC (tumour) samples 


\begin{tabular}{|c|c|c|c|c|}
\hline Parameters & IL-1 $\beta(15 / 23)$ & TNF- $\alpha(16 / 23)$ & IL-8 (11/23) & VEGF $(12 / 23)$ \\
\hline \multicolumn{5}{|l|}{ T Stage } \\
\hline $\mathrm{T} 1$ & - & - & - & - \\
\hline $\mathrm{T} 2$ & $6.7 \%$ & $6.25 \%$ & $9 \%$ & $16.7 \%$ \\
\hline T3 & $46.7 \%$ & $43.8 \%$ & $36.3 \%$ & $25 \%$ \\
\hline \multirow[t]{2}{*}{$\mathrm{T} 4$} & $46.7 \%$ & 56.25 & $54.6 \%$ & $58.3 \%$ \\
\hline & $(\rho=+.46464 ; p=0.04)$ & $\begin{array}{c}\left(\chi^{2}=10.977 ; p=0.004\right) \\
(\rho=+.654 ; p=0.001)\end{array}$ & NS & $(\rho=+.43264 ; p=0.004)$ \\
\hline \multicolumn{5}{|l|}{ M Stage } \\
\hline M0 & $66.7 \%$ & $68.8 \%$ & $63.6 \%$ & $78.3 \%$ \\
\hline \multirow[t]{2}{*}{ M1 } & $33.3 \%$ & $31.2 \%$ & $36.4 \%$ & $21.7 \%$ \\
\hline & NS & NS & NS & $\begin{array}{c}(\chi 2=5.856 ; p=0.016) \\
(\rho=+.534 ; p=0.001)\end{array}$ \\
\hline \multicolumn{5}{|l|}{ Stage } \\
\hline Ia & $0 \%$ & 0 & 0 & 0 \\
\hline $\mathrm{Ib}$ & $6.7 \%$ & 0 & 9.1 & 16.7 \\
\hline IIa & $6.7 \%$ & 0 & 9.1 & 0 \\
\hline $\mathrm{IIb}$ & $33.3 \%$ & 43.8 & 36.4 & 16.7 \\
\hline III & $20 \%$ & 25 & 9.1 & 25 \\
\hline \multirow[t]{2}{*}{ IV } & 33 & 31.2 & 36.4 & 41.7 \\
\hline & NS & $\begin{array}{c}\left(\chi^{2}=13.081 ; p=0.011\right) \\
(\rho=+.684 ; p=0.001)\end{array}$ & NS & $\begin{array}{c}\left(\chi^{2}=10.91 ; p=0.028\right) \\
(\rho=+.464 ; p=0.024)\end{array}$ \\
\hline \multicolumn{5}{|c|}{ Differentiation } \\
\hline Well & $67 \%$ & $62 \%$ & $72.7 \%$ & $63 \%$ \\
\hline Moderately & $6 \%$ & $18.75 \%$ & $9 \%$ & $19 \%$ \\
\hline \multirow[t]{2}{*}{ Poorly } & $27 \%$ & $18.75 \%$ & $18.2 \%$ & $18 \%$ \\
\hline & $\left(x^{2}=9.153 ; p=0.010\right)$ & NS & NS & NS \\
\hline \multicolumn{5}{|c|}{ Serosal invasion } \\
\hline Absent & $6.7 \%$ & 0 & & \\
\hline \multirow[t]{2}{*}{ Present } & $93.7 \%$ & $100 \%$ & & \\
\hline & NS & $\begin{array}{c}(\chi 2=7.886 ; p=0.005) \\
(\rho=+.586 ; p=0.03)\end{array}$ & NS & NS \\
\hline \multicolumn{5}{|l|}{ Lymph nodes } \\
\hline Absent & $13.3 \%$ & 0 & $18.2 \%$ & $16.7 \%$ \\
\hline \multirow[t]{2}{*}{ Present } & $86.7 \%$ & $100 \%$ & $81.8 \%$ & $83.3 \%$ \\
\hline & NS & $\begin{array}{c}(\chi 2=11.068 ; p=0.001) \\
(\rho=+.694 ; p=0.001)\end{array}$ & NS & NS \\
\hline \multicolumn{5}{|c|}{ Liver metastasis } \\
\hline Absent & $26.7 \%$ & $18.8 \%$ & $36.4 \%$ & $33.3 \%$ \\
\hline \multirow[t]{2}{*}{ Present } & $73.3 \%$ & $81.2 \%$ & $63.6 \%$ & $66.7 \%$ \\
\hline & $(\chi 2=2.813 ; \mathrm{p}=0.094)$ & $\begin{array}{c}(\chi 2=9.168 ; p=0.002) \\
(\rho=+.631 ; p=0.001)\end{array}$ & NS & NS \\
\hline \multicolumn{5}{|c|}{ Omental metastasis } \\
\hline Absent & $26.7 \%$ & $25 \%$ & $45.5 \%$ & $16.7 \%$ \\
\hline \multirow[t]{2}{*}{ Present } & $73.3 \%$ & $75 \%$ & $54.5 \%$ & $83.3 \%$ \\
\hline & $\begin{array}{c}(\chi 2=4.960 ; p=0.026) \\
(\rho=+.426 ; p=0.02)\end{array}$ & $\begin{array}{c}\left(\chi^{2}=7.304 ; p=0.007\right) \\
(\rho=+.564 ; p=0.02)\end{array}$ & NS & $\begin{array}{c}\left(\chi^{2}=7.340 ; p=0.007\right) \\
(\rho=+.565 ; p=0.005)\end{array}$ \\
\hline
\end{tabular}

Where $\mathrm{p}>0.05$ has been taken as significant;

( $\rho$ = Spearman's rho correlation co-efficient and shows linear correlation)

NS $=$ not significant.

Table 4: Comparison between gene expressions of genes with different parameters 
TNF-a: Out of 23 GBC samples, 69.6\% (16/23) showed an upregulated expression of TNF- $\alpha$ as compared to cholelithiasis samples $(\mathrm{p}=0.002)$. Thus the association is statistically significant with increase in stage, serosal invasion, lymph node involvement, liver metastasis and omental metastasis (Table 4) (Figure 2).
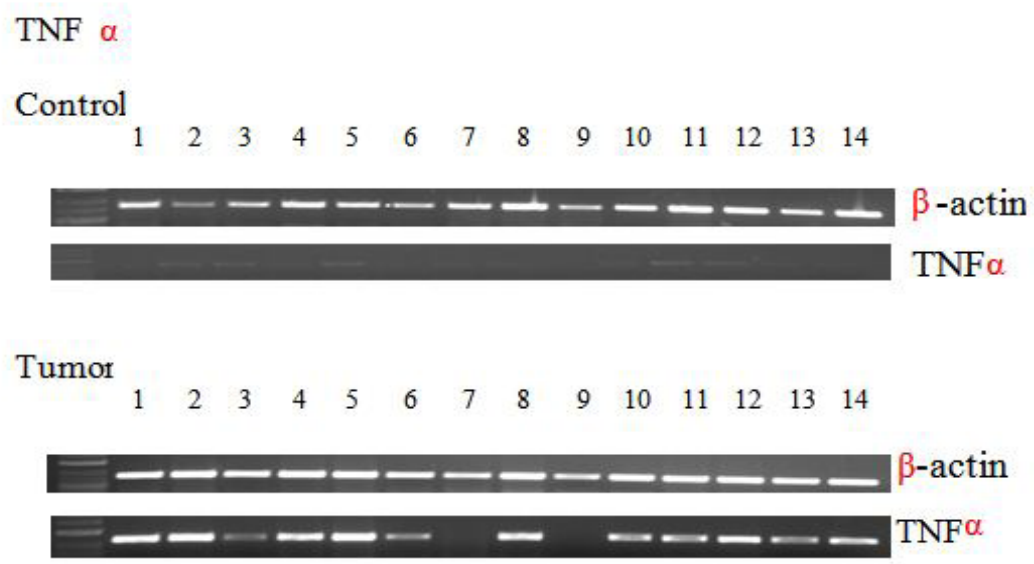

Figure 2: Image showing the positive expression of TNF- $\alpha$ in cholelithiasis (control) and GBC (tumour) samples

IL-8: IL-8 over expression has been observed in $47.8 \%(11 / 23)$ of the malignant samples $(\mathrm{p}=0.0082)$. Up regulation of IL-8 was significant (p-value $=0.0082)($ Table 4$)$ (Figure 3$)$.

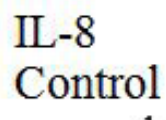

$\begin{array}{llllllllllllll}1 & 2 & 3 & 4 & 5 & 6 & 7 & 8 & 9 & 10 & 11 & 12 & 13 & 14\end{array}$

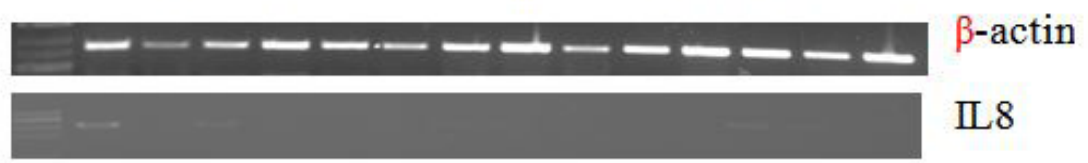

\section{Tumor}

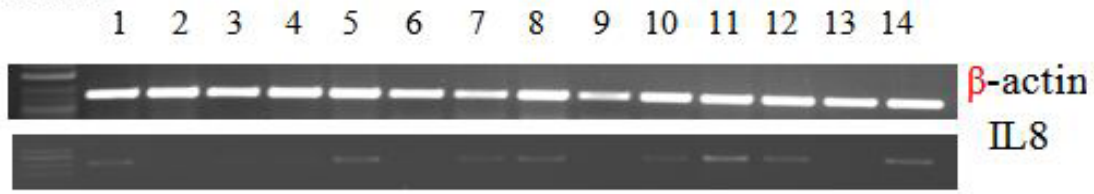

Figure 3: Image showing the positive expression of IL-8 in cholelithiasis (control) and GBC (tumour) samples

VEGF: VEGF over expression was seen in $52.17 \%(12 / 23)$ of the malignant samples $(\mathrm{p}=0.034)$. A positive linear co-relationship of VEGF with liver and omental metastasis of gallbladder carcinoma has been demonstrated in the present study (Table 4) (Figure 4).

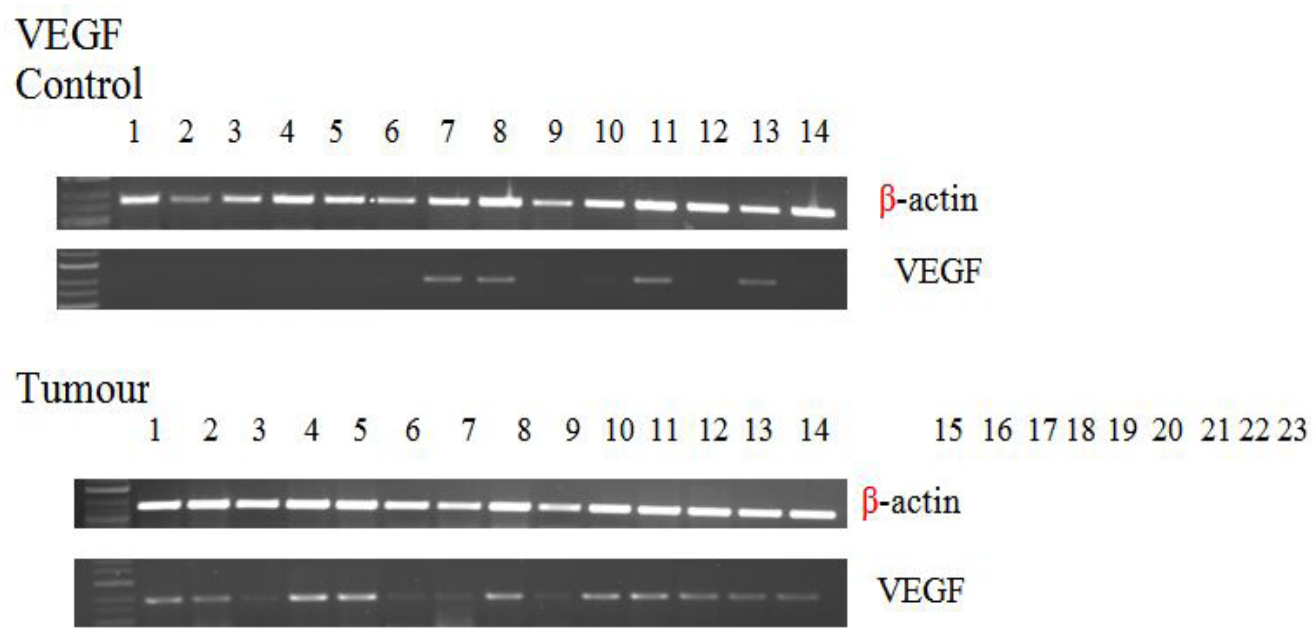

Figure 4: Image showing the positive expression of IL-8 in cholelithiasis (control) and GBC (tumour) samples 
IL-6: IL-6 showed no expression in both the cholelithiasis and GBC samples (Figure 5).

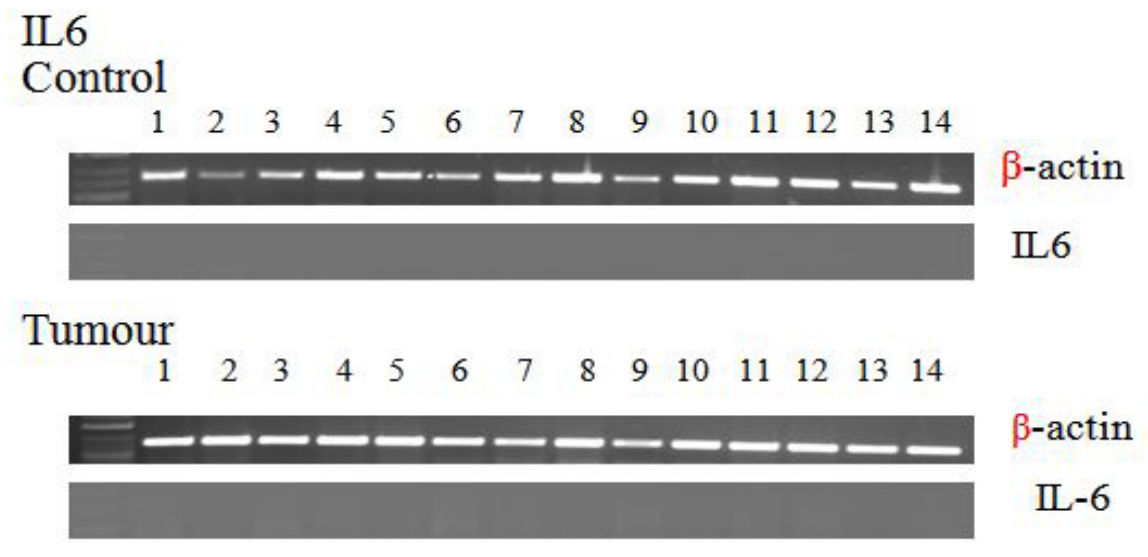

\section{Discussion}

Figure 5: Image showing no expression of IL-8 in cholelithiasis (control) and GBC (tumour) sample

Cytokines modulate the functional activities of individual cells and tissues both under normal and pathogenic condition. Cytokines affect nearly every biological process; these include embryonic development, disease pathogenesis, non-specific response to infection, specific response to antigen, changes in cognitive functions, and degenerative processes of ageing $[7,8]$. Recently many clinical studies have looked into the role of cytokines in the pathogenesis of cancer. Cytokines such as IL-1 $\beta$, IL- 6 and IL- 8 are now being regarded as main culprit molecules in the pathway of progression of chronic inflammatory process to carcinogenesis [9]. Therefore, we have evaluated the expression of different cytokines (IL-1 $\beta$, TNF- $\alpha$, IL -6, IL- 8 and VEGF) in GBC. TNF- $\alpha$ is released in response to infection and inflammation and can inhibit tumor development and progression [10]. TNF is a multifunctioning lymphokine produced by activated macrophages and lymphocytes [11]. We have found overexpression of TNF- $\alpha$ in $69.5 \%$ GBC samples compared to cholelithiasis. The expression of TNF- $\alpha$ is increased with the advance stage $(p=0.004)$ and lymph nodal metastasis of the cancer $(\mathrm{p}=0.001)$. Hence highest TNF- $\alpha$ expression was seen in $\mathrm{T}_{4} \mathrm{~N}_{2}$ tumour groups. TNF- $\alpha$ showed a positive linear correlation $(\mathrm{p}=0.005)$ with serosal invasion of the disease with over expression seen in $100 \%$ of serosal invasion cases. In a previous study, Kang et al [12] found a higher plasma level of TNF- $\alpha$ as compared to control in colorectal adenomas. IL- $1 \beta$ is known to have an association with tumor staging and metastasis [13]. mRNA TNF- $\alpha$ and VEGF expression were also elevated in chronic liver disease specimen [14]. IL-1 $\beta$ acts indirectly on cancer cells by stimulating lymphocytes to kill cancer cells and it is approved for treating metastatic kidney cancer and metastatic melanoma. It is also being investigated for the treatment of leukemia, lymphoma and cancers of the brain, colon, breast and prostate [15]. Other studies have also reported that IL- $1 \beta$ protein is produced in solid tumours like breast, colon, lungs and head and neck cancer [9]. In our study, we found a significant association between the expression of interleukin IL- $1 \beta$ and histological differentiation of cancer $(p=0.010)$. Of the $65.3 \%$ samples showing significant over expression, $67 \%, 6 \%, 26 \%$ were well, moderately and poorly differentiated respectively $(\mathrm{p}=0.0012)$. Carcinoma with liver metastasis showed a high IL-1 $\beta$ expression $(73.3 \%$ cases, $\mathrm{p}=0.094)$. Those with omental metastasis showed a positive linear correlation $(\mathrm{p}=0.026)$.

There is an accumulating evidence linking IL-6 to colon cancers. IL- 6 was also found to play a regulatory role on the proliferation of intestinal epithelial cells [16]. In colon cancer patients, serum levels of IL-6 were found to be highly elevated and positively correlated to tumor load [17]. In our study, IL-6 showed low expression in both tumour and cholelithiasis samples which indicates that it has no significant role in carcinogenesis of GBC. Another study reported that altered gene expression of IL-6 enhances tumor growth in cholangiocarcinoma. But a similar study by Vishnoi et al acclaimed that IL-6 polymorphism does not influence the susceptibility for GBC [18].

Although IL-8 showed a moderately increased expression in GBC, no definite association could be documented with any parameters in our study. IL- 8 mediates the recruitment and activation of neutrophils in inflamed tissue [13]. IL- 8 can be detected in synovial fluid from patients with various inflammatory rheumatic diseases and mucosal levels of IL- 8 are elevated in patients with active ulcerative colitis [5]. Kheirelseid et al also found a progressively increased expression of IL8 in tumour-associated normal, to polyps, to tumours in colorectal cancer by doing quantitative PCR [19].

VEGF is a signal protein produced by cells that stimulate vasculogenesis and angiogenesis [4], and has been found to play a major role in angiogenesis and metastasis [20]. VEGF has been found to be highly expressed in a broad range of human tumours [21]. We observed an equal expression of VEGF genes in tumour and cholelithiasis samples $(\mathrm{p}<0.05)$. Overexpression was seen in $52.17 \%$ cases of GBC. The amount of angiogenesis increases in a linear fashion with invasion of the disease $(p=0.006)$. Expression was strongly positive in metastatic samples. VEGF also showed a linear correlation with staging of the disease $(p=0.02)$. Petrenko et al [22] suggested a 76\% and 26\% increased expression of VEGF in GBC and cholelithiasis respectively. Similar observation about 
significantly higher VEGF expression has been made in breast cancer [23]. Results of other study also suggested that VEGF-A was highly expressed in GBC and correlated with poor prognosis [24]. Doval et al observed an overexpression of VEGF in about $34 \%$ of the cases. But they observed a decreased rate of overexpression and were found to be statistically associated with alive cases [25]. We reported a significant relationship between the expressions of TNF- $\alpha$, IL-1 $\beta$, IL- 8 and VEGF and GBC stage, grade and metastasis. However, no correlation was obtained between expression of IL- 6 and gallbladder carcinoma suggesting that its involvement in the pathogenesis and progression of the disease is unlikely.

\section{Conclusion}

In conclusion, these cytokines expression showed a higher expression level in gallbladder cancer and it also increase with the advance stage. Thus the results suggest that there is a role of these cytokines except IL-6 in gallbladder cancer progression.

The study has limitations in terms of its small sample size. However further studies with larger sample size are needed to substantiate association, causation between the two.

\section{Acknowledgement}

The Authors thank Dr. Sen Pathak and Dr. S Basu for critically reviewing this manuscript.

\section{References}

1. Perpetuo MD, Valdivieso M, Heilbrun LK, Nelson RS, Connor T, et al. (1978) Natural history study of gallbladder cancer: a review of 36 years experience at M. D. Anderson Hospital and Tumour Institute. Cancer 42: 330-5.

2. Carriaga MT, Henson DE (1995) Liver, gallbladder, extrahepatic bile ducts, and pancreas. Cancer 1: 171-90.

3. Diehl AK (1980) Epidemiology of gallbladder cancer: a synthesis of recent data. J Natl Cancer Inst 65: 1209-14.

4. Hanahan D, Weinberg RA (2000) The hallmarks of cancer. Cell 100: 57-70.

5. Trosko JE (2001) Commentary: is the concept of "tumour promotion" a useful paradigm? Mol Carcinog 30: 131-7.

6. Berenblum I (1985) Challenging problems in cocarcinogenesis. Cancer Res 45: 1917-21.

7. Muratore A, Amisano M, Viganò L, Massucco P, Capussotti L (2003) Gallbladder cancer invading the perimuscular connective tissue: results of reresection after prior non-curative operation. J Surg Oncol 83: 212-5.

8. Nakayama F (1991) Recent progress in the diagnosis and treatment of carcinoma of the gallbladder introduction. World J Surg 15: 313-4.

9. Philip M, Rowley DA, Schreiber H (2004) Inflammation as a tumor promoter in cancer induction. Semin Cancer Biol 14: 433-9.

10. Savill J, Dransfield I, Gregory C, Haslett C (2007) A blast from the past: clearance of apoptotic cells regulates immune responses. Nat Rev Immunol 2: 965-75.

11. McArthur MA, Sztein MB (2012) Heterogeneity of multifunctional IL-17A producing S. Typhi-specific CD8+ T cells in volunteers following Ty21a typhoid immunization. PLoS One 7: e38408.

12. Kang M, Edmundson P, Araujo-Perez F, McCoy AN, Galanko J, et al. (2013) Association of plasma endotoxin, inflammatory cytokines and risk of colorectal adenomas. BMC Cancer 13: 91.

13. Seril DN, Liao J, Yang GY, Yang CS (2003) Oxidative stress and ulcerative colitis associated carcinogenesis: studies in humans and animal models. Carcinogenesis 24: 353-62.

14. Hammam O, Mahmoud O, Zahran M, Sayed A, Salama R, et al. (2013) A Possible Role for TNF- $\alpha$ in Coordinating Inflammation and Angiogenesis in Chronic Liver Disease and Hepatocellular Carcinoma. Gastrointest Cancer Res 6: 107-14.

15. Okada F (2002) Inflammation and free radicals in tumor development and progression. Redox Rep 7: 357-68.

16. Risch HA, Howe GR (1995) Pelvic inflammatory disease and the risk of epithelial ovarian cancer. Cancer Epidemiol Biomarkers Prev 4: 447-51.

17. Palapattu GS, Sutcliffe S, Bastian PJ, Platz EA, De Marzo AM, et al. (2005) Prostate carcinogenesis and inflammation: emerging insights. Carcinogenesis 26: $1170-81$.

18. Vishnoi M, Pandey SN, Choudhury G, Kumar A, Modi DR, et al. (2007) Do TNFA -308 G/A and IL6 -174 G/C gene polymorphisms modulate risk of gallbladder cancer in the north Indian population? Asian Pac J Cancer Prev 8: 567-72.

19. Kheirelseid EA, Miller N, Chang KH, Nugent M, Kerin MJ (2013) Clinical applications of gene expression in colorectal cancer. Gastrointest Onco 14: 144-57.

20. Ohta Y, Endo Y, Tanaka M, Shimizu J, Oda M, et al. (1996) Significance of vascular endothelial growth factor messenger RNA expression in primary lung cancer. Clin Cancer Res 2: 1411-6.

21. Dirix LY, Vermeulen PB, Hubens G, Benoy I, Martin M, et al. (1996) Serum basic fibroblast growth factor and vascular endothelial growth factor and tumour growth kinetics in advanced colorectal cancer. Ann Oncol 7: 843-8.

22. Petrenko O, Moll UM (2005) Macrophage migration inhibitory factor MIF interferes with the Rb-E2F pathway. Mol Cell 17: 225-36.

23. Srabovic N, Mujagic Z, Mujanovic-Mustedanagic J, Softic A, Muminovic Z, et al. (2013) Vascular endothelial growth factor receptor-1 expression in breast cancer and its correlation to vascular endothelial growth factor A. Int J Breast Cancer 2013: 746749.

24. Letelier P, Garcia P, Leal P, Ili C, Buchegger K, et al. (2014) Immunohistochemical expression of vascular endothelial growth factor A in advanced gallbladder carcinoma. Appl Immunohistochem Mol Morphol 22: 530-6.

25. Doval DC, Azam S, Sinha R, Batra U, Mehta A (2014) Expression of epidermal growth factor receptor, p53, Bcl2, vascular endothelial growth factor, cyclooxygenase-2, cyclin D1, human epidermal receptor-2 and Ki-67: Association with clinicopathological profiles and outcomes in gallbladder carcinoma. J Carcinog 13: 10 . 


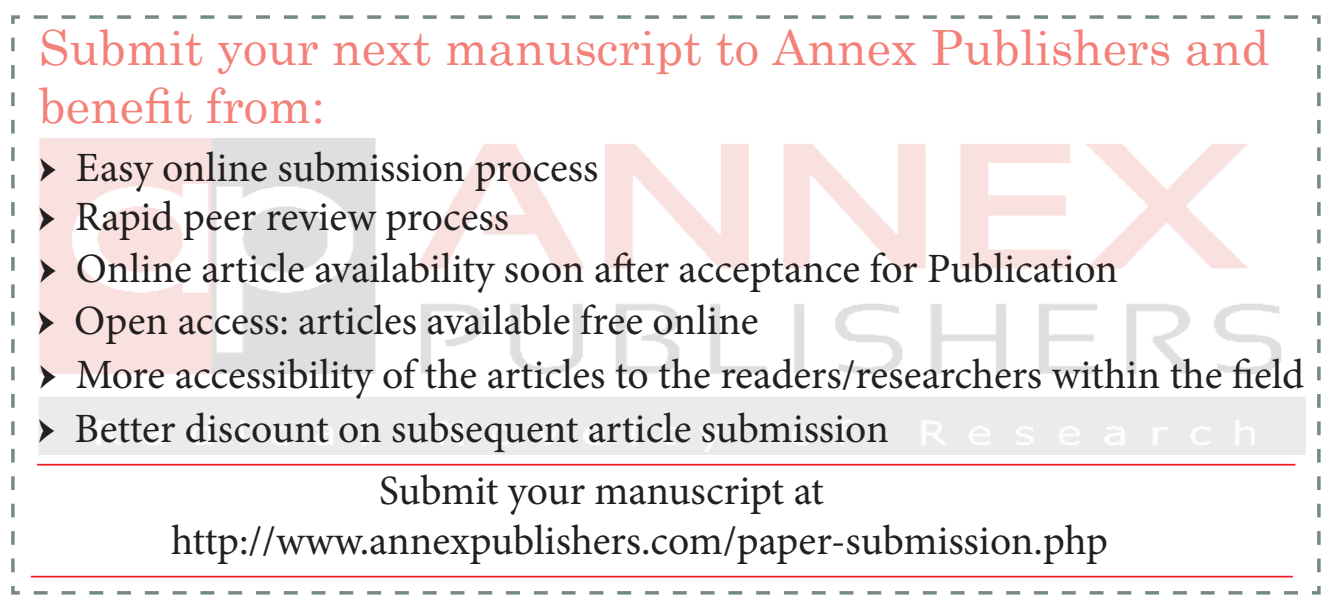

